\title{
Cultural otherness and disaster news: the influence of western discourses on Japan in US and UK news coverage of the 2011 Great East Japan Disaster
}

The Great East Japan Disaster of 2011 provides an important case study to evaluate how western media cover Japan. Employing a critical discourse analysis of coverage in The New York Times, the Guardian and The Observer this article seeks to examine how Japan and the disaster-affected communities of Tōhoku were represented through the context of this disaster. The analysis revealed the presence of a cultural framework, enacted during the response phase of the disaster news cycle to explain how people in Japan were coping in the aftermath of the disaster, which was premised on a discourse of cultural otherness. The textual elements that underwrote this discourse included a tendency to draw on stereotypes and in the way culture was employed to provide context to individual stories. The analysis also acknowledges how forms of bias circulated through other discourses, in particular when covering the nuclear crisis at Fukushima. The article argues that this discourse of cultural otherness is, in part, attributable to the features of disaster journalism, rather than a lack of familiarity on the part of journalists with the cultural context.

Keywords: Great East Japan Disaster; disaster reporting; critical discourse analysis; cultural otherness; stereotypes; US and UK news media

The magnitude 9.0 earthquake that struck Japan on 11 March 2011 triggered a series of tsunami waves that devastated coastal communities in the north east of the country, leaving over ten thousand dead or missing and many more displaced from their homes. The disaster disrupted the power supply and cooling systems at the Fukushima Daiichi nuclear plant, which led to the partial meltdown of three reactor cores and the release of radioactive materials. It was 
designated at the time as a level 7 accident on the IAEA event scale and described as the most significant nuclear emergency since Chernobyl (Kushida, 2012).

This cascading disaster became the focus of global news media attention in the days that followed. The existing scholarship shows that it was discursively constructed in the international media in terms of the nuclear crisis (Pantti, Wahl-Jorgensen and Cottle, 2012), with coverage reflecting well-trodden discourses on nuclear power by enacting frames that emphasized uncertainty and anxiety concerning the risks posed by radiation (Iannarino, Veil, Cotton, 2015).

While there is a significant body of scholarly work on Japanese media coverage of the tsunami and recovery in Tōhoku (McCarthy, 2014; Rausch, 2014; Samuels, 2013; Takekawa, 2014), empirical research evaluating international or western media coverage has more often focused on the nuclear crisis (Iannarino, Veil, Cotton, 2015; Sakai, 2015; Tkach-Kawasaki, 2012) with only limited attention paid to news reporting across this multiple overlapping disaster. The broader objective of this paper, therefore, is to document and analyse news media coverage of both the tsunami, and its impact on disaster-affected communities, and the nuclear crisis.

Despite some commentators writing at the time, noting that western media coverage of the disaster seemed to rely on stereotypical representations of the Japanese, (Huang, 2011; Rees, 2011), this issue has so far remained at the peripheries of academic research. This article seeks to address this gap by examining how Japan and the disaster-affected communities in Tōhoku were represented through print and online coverage of the disaster in The New York 
Times (US) and the Guardian/The Observer (UK). Two newspapers that are widely acknowledged as amongst the most read quality titles in terms of their global readership and reach (Cision, 2016; Press Gazette, 2016).

\section{Mediation of disaster}

In today's global media system, disasters are constructed through the interactions between old and new media. Digital technologies have changed how news is aggregated and delivered to audiences, offering greater opportunities for alternative sources of information to be reflected in mainstream news and providing spaces, such as through social platforms, for public discourse (Cottle, 2014; Guo, Holton and Jeong, 2012). The flow of information across social networks is now also recognized as a vital element of disaster response and is increasingly integrated into disaster planning (McCormick, 2016).

Many of the images of disaster that emerge in their immediate aftermath are now provided by people caught up in and eyewitnesses to events, with such citizen accounts contributing to how disasters are communicated, represented and understood (Allan, 2014). This material documenting disasters and their impacts is very quickly made available and shared across social networks, which in turn is picked up and integrated into mainstream news coverage.

The value of such eyewitness accounts is that they are able to offer alternative perspectives on disaster (Farinosi and Treré, 2014), providing a more complete picture of their impacts (Greenberg and Scanlon, 2016). This rich, compelling content also contributes to more authentic representations of disaster, thereby enhancing emotional proximity for audiences (Pantti, 2012: 206). 
Although the contemporary media environment is marked by greater diversity and complexity, mainstream media, defined as the national, regional and global providers of broadcast, online and print news, remain important in informing audiences about the impacts and consequences of disaster (Franks, 2013). International news organisations, including newspapers, are able to maintain a global reach (Himelboin, Chang and McCreey, 2010; Watanabe, 2012; Wu, 2007) and therefore shape how disasters become signified and understood (Greenberg and Scanlon, 2016: 7; Himelboin, Chang and McCreey, 2010; Wu, 2007).

Research focusing on how the mainstream news media cover disaster has identified a tendency for reporting to follow familiar templates, often focusing on their acute impacts (Houston, Pfferbaun and Rosneholtz, 2013; Pantti, WahlJorgensen and Cottle, 2012) but failing to adequately explore the causes that aggravate their effects (Ploughman, 1995).

When covering foreign disasters, it is their proximity, 'geographically, politically or culturally', that determines whether they capture media attention (Gans, 1980: 36; Joye, 2010), with those involving elite nations (Galtung and Ruge, 1965) more likely to make the news. Disasters that affect regions or countries outside of the core are only 'made visible' therefore when they involve a significant loss of life (Gans, 1980: 36; Pantti, Wahl-Jorgensen and Cottle, 2012). Another line of argument is that the newsworthiness of a disaster event is related to the number of western victims and its potential to disrupt dominant economic interests (Benthall, 1993; Joye, 2010).

Research has also considered how the news media may contribute to a process of othering when covering disaster events, reinforcing colonial 
discourses of dependency by presenting an image of 'helplessness' for those communities affected by disaster (Bankoff, 2001; Benthall, 1993: 187). This can lead to 'compassion fatigue', with audiences unable to relate to a disaster event and its impacts. Conversely, others propose that when narrativising disaster the news media may enact pity, with stories crafted in such a way as to facilitate affective engagement amongst audiences (Chouliaraki, 2006).

The mainstream news media therefore remain integral to the communication of disaster (Franks, 2013), inscribing them with different meanings' and 'how they become known or responded to' (Cottle, 2014: 17).

\section{Western discourses on Japan}

Western discourses on Japan have often reflected an orientalist image, emphasizing its difference or cultural otherness from the West. This image of Japan is premised upon an essentialist interpretation of culture, which assumes that differences between cultures, defined as the values and beliefs that shape the behaviours of a group of people, are fixed and attributable to their intrinsic characteristics (Morris, 2011). Consequently, human beings act as bearers of a culture that define and differentiates them from others (Girilo, 2003:158). Descriptions of Japanese society have, for example, often emphasized the importance of group orientation, community and hierarchy as inherent features of Japanese culture (see Hendry, 2013), with such patterns of behaviour cited as evidence of a 'holistic culture' (Ryang, 2004).

Iwabuchi (1994) maintains that this western orientalist discourse has also served to reinforce a discourse in Japan, one propagated by elites, that Japan was different from the West, the discursive construction of 'self-orientalism.' One 
manifestation of this was the sub-discourse of Nihonjinron, a genre of literature or theories about Japanese culture and society that presented Japan as distinct from other cultures, which became more prominent as Japan established itself as a major economic power in the 1970s. This discourse was enacted to explain Japan's economic success (see Ishihara, 1991) but also served to counter an antiJapanese discourse that reemerged in the West in response to Japanese ascendancy as a global power. A sentiment more keenly felt in the US due to Japan's perceived potential to challenge its hegemonic position in the international system (Morris, 2011: 138).

Contemporary research that has drawn on people's experiences of life in Japan demonstrates that, common to most advanced industrial societies, Japanese society and culture is characterized by differentiation and complexity (Kawano, Roberts and Long, 2014). Rapid technological change, emerging patterns of consumption (Roth, 2014) and shifts in attitudes and values (Alexy, 2010), processes facilitated by social change within Japan and the external dynamics of globalization, create space for the recognition of heterogeneous cultural values, norms and practices (Iwabuchi, 2015).

Despite this, western discourse on japan, exemplified within the political, public and media sphere, have continued to emphasize cultural otherness, premised on an essentialist understanding of identity and culture (Miller, 2014). Otherness, in the context of culture, therefore can be defined as representations that show elements of culture that are perceived to be different from the familiar backgrounds or experience of the self (Giovanni, 2003). For the present research, the referent self being western audiences. 
While generally news about Japan is limited (Hammond, 1997), western media have tended to report Japan in a distorted way (Levick, 2005; Hinton, 2014; Seaton, 2005). A study focusing on the British media, for example, identified how otherness acts as a news value that guides reporting on Japan and even stories with strong news value can be 'treated as a springboard for musing about the national character' (Hammond and Stirner, 1997: 88).

In a similar vein, Levick (2005) criticized US media coverage of Japan, identifying four forms of bias: the overuse of war metaphors, a tendency to describe Japan as a monolithic entity, the adoption of a patronizing tone when describing Japan's culture and a failure to acknowledge and assimilate Japanese perspectives into reporting.

Stereotypes have also been shown to influence the selection and presentation of stories in foreign news reporting on Japan (Breger, 1992; Moeller, 1996). Seaton (2005) found that stereotyping was reflected in the over and underrepresentation of particular perspectives on Japan, for instance the prominence afforded to nationalist voices, misrepresentation, through the use of journalistic shorthand, by, for example, equating the position adopted by the government of Japan with Japanese opinion. Stereotyping is also revealed in a tendency to draw attention to stories that emphasize the 'more eccentric and exotic aspects of Japanese society' or 'generalize about the national character' (Hammond and Stirner, 1997: 88).

While the 'kernel of truth hypothesis' posits that stereotypes are not always false (Seiter, 1986), they oversimplify and are distortions that 'could be used to discredit or promote certain social groups over others' (Ibroscheva and Ramaprasad, 2008:4). From a constructive perspective, journalists draw on 
stereotypes as shared representatives that are part of the way people view 'themselves and their relations with others' and as a form of social representation 'employed in communication and circulating in the culture' (Hinton, 2016: 224). A psychological view (Tajifel, 1969), however, premised on the understanding that individuals serve as the source of stereotyping would propose that journalists' cognitive biases influence the presentation of news (Lasorsa and Dai, 2007). Moreover, that stereotypes are shortcuts that may be used to allow audiences to make sense of events that are outside their 'immediate perceptual grasp’ (Shoemaker and Reese, 1996: 36). Common to both perspectives, and attributable to journalistic practice, is that stereotypes are engaged to allow audiences to make sense of events and present stories that are 'comprehensible, appealing and relevant' (Gurevitch, Levy and Roeh, 1991: 206).

Mayes and Rowling (1997: 118) suggest that one reason western news reporting tends to reinforce cultural otherness is due to the 'editorial perceptions of what journalism on Japan should be.' With many journalist, in particular those writing for the quality newspapers considered to be Japan specialists, editors do not always have sufficient knowledge about Japan to evaluate stories objectively and will therefore often favour stories that reflect Japanese stereotypes.

Although there exists a gap in literature concerning contemporary news media coverage of Japan, there is sizeable body of recent work that considers the representations of Japan through popular culture, including mass media products such as film and television (See Daliot-Bul, 2008; Goldstein-Gidoni, 2005; Iwabuchi, 2003). This research has identified how characters drawn in certain films reinforce stereotypical images of Japan, with Sofia Coppolla's Lost in 
Translation a notable case in point (Brown, 2014). Others, however, argue that the reach and influence of contemporary Japanese popular culture such as manga and anime may also lead to a new layer of images and sensibilities toward the country (Otmazgin, 2013).

The central research objective this article seeks to address is to examine whether these discourses of difference and cultural otherness were articulated through The New York Times (hereafter NYT) the Guardian and its Sunday sister-title, The Observer's, coverage of the Great East Japan Disaster. While the sampling approach described below was designed to capture all articles reporting on the disaster, including the tsunami and the nuclear crisis at Fukushima, the analytical focus is orientated toward evaluating how these discourses were reproduced through the mediated representations of Japan and disaster-affected communities in Tōhoku in the context of this news event.

\section{Methodology}

To address these objectives, a critical discourse analysis (CDA), adapting van Dijk's (1993; 2009) and Fairclough's (2003) criteria for the study of discourse within its social and cultural context, was conducted on reporting carried in print and online editions of The NYT and the Guardian/The Observer.

These publications are not representative of the ideological spectrum of news in the American and UK media and all could be described as left-leaning or liberal in their political affiliation and outlook. They were selected, however, due to the position of The NYT and the Guardian, as the two most read quality English-language digital newspaper titles (Sweeney, 2013), and when combining 
print and online readership, their status as the most read quality newspaper in the US and UK respectively (Cision, 2016; Press Gazette, 2016).

The decision to focus on newspapers, as opposed to other media forms, was due to their continued influence on global news agendas (Roy, 2012) and ability, alongside international news agencies, to maintain a global reach (Himelboin, Chang, and McCreey 2010; Watanabe, 2012; Wu, 2007) and provide a platform for discussion and opinion on international events (Golan and Lukito, 2015; Ha, 2015), in particular in the sphere of crisis news (Reese and Lewis, 2009).

The sample for the CDA was produced by searching for relevant terms, including Japan and disaster; Japan and tsunami; Fukushima on the Factiva database, across print and online editions of The NYT and the Guardian/The Observer newspapers. The analysis focuses on the first month of the disaster cycle, with the sample including all articles published between 12 March 2011 and 11 April 2011. A first sift removed duplicate and irrelevant articles, which produced an initial sample of 347 articles (209 from the NYT and 138 from the Guardian/Observer).

A quantitative mapping analysis, which is not reported in detail in this article, was first used to produce a typology of coverage. As part of this process, each article was coded for primary and secondary topic themes. This revealed that a number of items only made a passing reference to the disaster or nuclear crisis when exploring other associated issues; most prominent in this initial sample were stories about nuclear power, energy policy and the repercussions of the disaster for the global economy. 
Insert Figure 1 here.

Following this initial mapping analysis, a second stage sift was carried out to produce a final sample for the CDA reported in this article. All news articles, features, opinion and editorials, dealing with the disaster, nuclear crisis and its impact on Japan were included. Those that did not fulfil these criteria and only made a passing reference to the disaster were excluded. This yielded a total of 109 items from the NYT and 106 from the Guardian $(n=90)$ and The Observer $(n=16)$ that formed the sample for analysis.

CDA is employed here to explore how prevailing discourses on Japan, those that have articulated difference and cultural otherness, were expressed through coverage of the 2011 disaster in The NYT and the Guardian/The Observer newspapers. As CDA aligns with an interactionist approach to discourse, which recognizes that discourses 'create representations of the world that reflect as well as actively construct reality '(Joye, 2010: 590), it seeks to analyse texts (here defined as news media coverage) and their meanings by recognising the context in which they are produced. For news, both discursive practices, such as organisational and journalistic routines, and social practices, the factors external to journalism, ideology, values and social system, shape the production and reception of news media texts (Fairclough, 1995; 2003; Philo, 2007; Richardson, 2007).

CDA also requires the researcher to recognize how hierarchies of power or 'discursive marginalisation' may be present in discourse and the discursive strategies that maintain and reproduce inequality (van Dijk, 1993; 2009). It has therefore been used as a methodological approach to examine media 
representations of distant suffering and understand how news coverage of crisis and disaster may maintain and construct cultural difference (Leung and Huang, 2007; Joye, 2010;).

The CDA employed in the present research first examined the structural features of the text. This stage of the analysis focused on the narrative structure, conceptual and thematic patterns evident in the texts, for example by analysing the structure of reports, the prominence afforded to the different aspects of the tripartite disaster, the foregrounding and backgrounding of other issues in reports or the types of stories that were introduced, their different elements and how they were used to offer insights into post-disaster Japan, for example. These macrostructures have been shown to be most important in defining the overall meaning and coherence of discourse (van Dijk, 1988: 33) and also reflect the 'ideological factors' that determine newsworthiness (Bednarek and Caple, 2014). In addition, the analysis also considered relevant micro features of the text, vocabulary, terms and descriptions, in particular those that pertained to Japan and disaster-affected communities, for instance specific words and metaphors to depict the post-tsunami environment and mood in Japan concerning the nuclear emergency at Fukushima. This stage of the analysis also sought to identify the presence of social actors (Fairclough, 2003), by focusing on the sources given voice but also excluded from coverage of the disaster and their function within texts, for example the position that they adopt or evidence they corroborate. It also considered the description and role assigned to particular sources since this is significant in evidencing the perspective from and authority which sources may speak, for instance whether a description assumes that a source is representative of expert opinion on nuclear power. 
While more recent approaches to CDA have also encompassed multimodal texts, it is important to note that analysis here was not extended to include visual elements, only focusing on written news discourse. In part, this was due to visual discourses on the Japan disaster to some degree being addressed by existing research that has explored the role of citizen images in communicating disaster and crises (see Pantti, 2013).

Following this descriptive stage (Fairclough 2003), these textual elements were then examined in the context of the discursive practices that shape news, for example the organisational and logistical factors that are part and parcel of news production (Philo, 2007). It also attempts to relate the texts to the broader discourses on Japan, in particular those that focus on descriptions and reception of Japanese culture, and positions adopted toward Japan. It is this context specific analysis that provides insights into the relationships between discourses and their socio-cultural functions (van Dijk, 2009).

\section{The disaster cycle}

The analysis is presented by focusing on three overlapping discursive phases of the disaster cycle. The rationale for organising the presentation of the findings around these three stages is to relate the textual characteristics of media coverage to different stages of the disaster cycle, from the immediate postimpact stage, through the response phase and into the initial recovery stage.

First discursive phase: post-impact

During the first discursive phase, which includes items published between 12 March and 15 March, coverage across the three publications was very similar, as 
it communicated the scale of destruction, for example through quantification by providing initial estimates of the number dead and missing and in the use of rich visual imagery (Pantti, Wahl-Jorgensen, Cottle, 2012: 52), with the tsunami described as a 'wall of water' (Power, Quake and Tsunami Devastate Northern Japan, The New York Times, 12 March 2011; In the Aftermath of Disaster, Survivors Search a Landscape of Loss, The New York Times, 15 March 2011) and 'a wave of death' (Japan's earthquake: A wave of death, the Guardian, 12 March 2011) in accounts of the disaster scene.

Descriptions of the disaster were, in some instances, based on direct testimony of survivors from disaster-affected communities, presenting short vignettes of survival and loss. The rendering of a cultural framework was, however, largely absent from coverage at this phase of the disaster cycle.

A range of different sources featured in reports, with Japanese politicians and administrators, including local officials from disaster-affected towns and cities, and representatives of Japan's nuclear power industry, prominent. One quote, attributed to Naoto Kan, the Japanese Prime Minister at the time of the disaster, which described the situation in Japan as the most severe crisis that the country had faced since World War 2, recurred across this discursive phase, appearing in a number of different items within the sample.

As fears grew over the nuclear situation at Fukushima, a discourse of risk was a consistent position adopted in the coverage. Two textual elements contributed to this discourse. First, although often thematic in its orientation, coverage tended to use the crisis as an avenue through which to explore a range of issues related to the use of nuclear energy in Japan. News and comment pieces, for example, evaluated the critical systems and safety features in place at 
Fukushima (Thousands told to evacuate in nuclear plant emergency: Spectre of Chernobyl as experts warn that order to flee homes signals a serious problem at power station in tsunami zone, Guardian, 12 March 2011) and highlighted criticisms over nuclear safety (Crisis at Pair of Reactors Underscores Japan's Fear Of the Nuclear Industry, The New York Times, 13 March, 2011), which served to amplify the potential risk of nuclear meltdown and its consequences. Second, international actors, often described as 'nuclear power experts', featured prominently in the news coverage, emphasising the gravity of the situation at Fukushima. These sources were quoted, sometimes within the same article, as challenging the initial assessment provided by 'Japanese sources', who downplayed the prospect of the situation evolving into a serious nuclear emergency (See Evacuations ordered near two nuclear power plants after warnings of small leaks, The New York Times, 12 March 2011; Nuclear Crisis is Worst in Decades, The New York Times, 13 March 2011; Disaster in Japan: Echo of Chernobyl: Experts say Japan is following 'pattern of denial' over radiation, the Guardian, 15 March 2011).

There were, however, differences between the newspapers in the way this critical position was articulated. The NYT relied more on the views of USbased experts, whose ability to comment authoritatively, was attributed to their knowledge of the technology, with three of the six reactors at the Fukushima plant manufactured by General Electric, an American multinational (In Stricken Fuel-Cooling Pools, a Danger for the Longer Term, The New York Times, 14 March 2011).

At this discursive phase allegations also emerged of mismanagement of the response to the nuclear crisis. Initial reviews of the Japanese media coverage 
identified that these criticisms centred on the timeliness and accuracy of information released to the public (McNeil, 2013; Samuels, 2013). The way these concerns were articulated through reporting in The NYT and the Guardian/The Observer are significant in evaluating how discourses on Japan were reproduced through coverage of this news event. First, they intimated an assumed position of western superiority (Levick, 2005), expressed through the perspectives provided by international or US experts and their view that knowledge and capacity gaps limited a domestic response to the crisis. Even if we accept the validity of concerns raised by these experts, then the tendency to position them as oppositional voices within the texts helped to serve this ideological function (Hinton, 2014). Second, by failing to distinguish between the different actors, with information often merely attributed to 'Japanese sources', it served to present their perceived failings as those of 'Japan' or the Japanese instead of identifying the different agencies with responsibility for managing the crisis (Levick, 2005).

\section{Second discursive phase: response and the post-disaster environment}

Looking beyond the initial reporting, the second discursive phase represents a shift in the disaster news cycle, where coverage also began to consider the disaster's impacts. In comparison with the first, this second stage was a longer time period, running from 16 March until 26 March.

Most significant during this phase was the foregrounding of a cultural framework enacted to explain how people in Japan were coping and responding to the disaster and nuclear crisis. This was reflected in the presence of stereotypical representations of the Japanese when describing the plight of 
disaster-affected communities in Tōhoku and through the exposition of aspects of Japanese culture used to contextualize stories and coverage of associated issues emerging at this stage of the disaster cycle. Both these textual elements, the analysis argues, served to underline a discourse of cultural otherness In The NYT this discourse was evident when reporting focused on the conditions in evacuation shelters, where life in the shelters was depicted through reference to Japanese cultural practices. In the example below the custom of removing shoes before entering the home is used to show how people were adapting to life in the public shelters.

\footnotetext{
'Those in the shelters try to maintain the orderly routines of normal Japanese life, seen in the tidy rows of shoes and muddy boots at the doorway to the shelters, where everyone is in socks.' (Misery and Uncertainty Fill Up Shelters, The New York Times, 17 March 2011).
}

This discourse was also articulated when coverage evaluated how those living through the disaster were able to cope, with some pieces suggesting that an explanation lied in Japanese culture. In the texts, as commentators writing at the time noted (Huang, 2011; Rees, 2011), there were a number of references to the 'stoicism', 'perseverance', 'spirit' and 'forbearance' of the Japanese, as demonstrated by the two examples that follow:

The gratitude and politeness of the refugees is striking, though for the moment it may reflect relief about surviving the disaster as much as the fabled Japanese spirit of forbearance (Disaster in Japan: A shortage of petrol and food, and too many bodies to 
bury: An estimated 10,000 people have died in Ishinomaki, the Guardian, 16 March 2011).

'This communal spirit is apparent at many shelters, some of which are run by community volunteer groups who donate and cook the food, and even clean the overused toilets.' (Misery and Uncertainty Fill Up Shelters, The New York Times, 17 March 2011).

A discursive position derived from a perspective of cultural otherness was also evident in comment and opinion editorials on the disaster. NYT columnist Nicholas Kristof asked what 'America' could learn from Japan, describing how the Japanese 'selflessly subsume their own interests for the common good' and dwelling upon the contrasts between collectivist values and 'American individualism.' In this piece, the presence of stereotypes illustrated this discourse, as the excerpt below indicates:

\footnotetext{
'There's a kind of national honor code, exemplified by the way even cheap restaurants will lend you an umbrella if you're caught in a downpour; you're simply expected to return it in a day or two. If you lose your wallet in the subway, you expect to get it back.' (The Japanese Could Teach Us a Thing or Two, The New York Times, 20 March 2011).
}

Ian Jack posed a similar question in his weekly column for the Guardian stating:

'We think of stoicism as a very British virtue-all 'Blitz spirit' and 'women and children first' - but would we react to a disaster with the kind of resilience the Japanese have.' (We all know the slogan Keep Calm and Carry On, but would we? the Guardian, 19 March, 2011). 
Such references to Japanese stoicism and self-sacrifice were symptomatic of a discourse of cultural otherness. Stereotypes, those that underlined the strength of collectivist values for example, was one textual characteristic, used to communicate how people were coping in disaster-affected areas (Rees, 2011). As a representational process, it was premised on an essentialist interpretation of Japanese culture and constructed a response to disaster that seemed to be particular to the Japanese.

While some have argued that the supposed cultural traits highlighted in news media coverage were exemplars of positive descriptors, used to express admiration for Japan and the Japanese (Huang, 2011), at the same time they served to normalize a discourse of difference.

It is important to note that during this discursive phase there were also other opinion pieces, some originally published in Japanese newspapers and translated into English, that made reference to national or cultural characteristics, as illustrated by the except below from an article authored by novelist Ryu Murakami:

The Japanese are often said to abide faithfully by the rules of the "group" and to be adept at forming cooperative systems in the face of great adversity. That would be hard to deny today. Valiant rescue and relief efforts continue nonstop, and no looting has been reported (Amid Shortages, a Surplus of Hope, The New York Times, 17 March 2011).

Another, pointed toward the international media coverage of Japan, suggesting that a shared value of community or 'public-mindfulness' should be a source of pride and a premise for national renewal. 
I hear that the foreign media has been reporting with amazement the calmness and moral behavior of the Japanese faced with the disaster. But actually this was a surprise to the Japanese themselves. "Yeah, we can do it if we put our minds to it." "We aren't so bad as a whole nation after all. (For A Change, Proud to be Japanese, The New York Times, 17 March, 2011).

These items are also suggestive of the presence of a counter discourse, one that presented a more nuanced appraisal of post-disaster behaviours. Murakami described, for instance, how out of necessity the disaster had led some people to act selfishly, panic-buying or hoarding food (Amid Shortages, a Surplus of Hope, The New York Times, 17 March 2011). Another article, published in the Guardian, explained how survivors living through the disaster were 'being worn down by a widening humanitarian crisis' and highlighted incidences of theft and violent crime reported in the disaster-affected region (Survivors: Mr Suzuki was burgled while visiting his family shrine. He's lost his sense of trust, the Guardian, 21 March 2011).

A further feature of coverage that exemplified the presence of a discourse of cultural otherness was for elements of Japanese culture, those that are familiar to western audiences as recognisable images of Japan, to be used to contextualize reporting on the tsunami and its effects. Two pieces published in the Guardian, for example, told the story of Chikano Fujima, identified as the 'last Geisha' in Kamaishi City, Iwate. The first, alongside the accounts of other survivors, described: 
Chikano Fujima, an 85-year-old geisha, who had to leave her kimonos behind when she was carried to safety just moments before the tsunami tore through her home. (Stories from across the disaster zone, 18 March, 2011).

In the second, a follow up piece, reported how she had turned down on offer of temporary shelter to continue to work in Kamaishi to 'keep the town's geisha tradition alive' (Town's geisha, 85, pledges to keep working, the Guardian, 24 March, 2011).

Towards the end of this discursive phase, two weeks on from the earthquake and tsunami, a further thematic pattern emerged as the coverage identified events that illustrated how life in 'Japan' had returned to a semblance of normality. Contextual reporting to some of these stories also explored aspects of Japanese culture and society. An article that reported a short delay in the start of the baseball season, for example, considered how deference to the group shapes the tone of discussion and decision-making in Japan, with the postponement of the opening game described 'as one that spoke volumes about the art of compromise and sacrifice in Japan' (A baseball loving nation delays its first pitch but not without delay, The New York Times, 21 March 2011). In another, alongside moving accounts of school graduation ceremonies that had taken place in towns affected by the tsunami, the article also explored the cultural significance of spring to the Japanese and its relevance to the start of the school year (Diplomas and an Uncertain Future for Japanese Pupils, The New York Times, 23 March 2011).

Beyond the disaster's immediate impact, it is inevitable that news stories will use culture as a framework to provide context and aid understanding 
(Gurevitch, Levy and Roeh, 1991). It is consequence of the discursive practices of journalism, one that the analysis here suggests may have a stronger influence on the characteristics of coverage in the quality press, or at least those that are liberal in their orientation, where more space is available to provide context and in-depth analysis.

The difficulty journalists face, even those that have a deep understanding of this cultural context, is that the necessity to draw on recognisable western images of Japan when constructing narratives will serve to reproduce and extend a discourse of cultural otherness. This interpretation is in contrast to that offered by other analyses that suggest it is in fact a lack of familiarity with the cultural context that leads to distortions in reporting (Louw, 2004).

\section{Third discursive phase: consequences and recovery}

The third discursive phase, which includes items published between 27 March and 11 April, was marked by a thematic shift, as coverage focused more on the consequences and longer-term implications of the tripartite disaster for Japan. Two features of coverage prominent during this period were a clearer articulation of responsibility for the mismanagement of the nuclear crisis, and the emergence of a consensus narrative when considering how Japan will move forward and recover from the disaster.

There were further criticisms of the response to the nuclear crisis but during this phase 'international experts' were positioned more clearly as appropriating blame to the nuclear industry in Japan. These perspectives were reflected in pieces that raised concerns about an apparent disregarded of tsunami risks to nuclear power facilities in Japan (Nuclear Rules in Japan Relied 
on Old Science, The New York Times, 27 March 2011), failures to identify current and future risks at the Fukushima plant (US Sees New Threats at Japan's Nuclear Plant, The New York Times, 6 April 2011) and the reliability of radiation readings provided by Tokyo Electric Power Company (TEPCO) (Radiation Errors Erode Confidence in Power Company, New York Times, 6 April 2011; Company Cites Broken Gauge, Not Damage, in Radiation Spike, The New York Times, 10 April 2011).

An additional element that underwrote this critical position was disparaging assessments, often attributed to expert sources, of Japan's nuclear power industry. One piece, published in The New York Times, described how the accident at Fukushima was due to a 'cascade of stupid errors' (Nuclear Rules in Japan Relied on Old Science, The New York Times, 27 March 2011). In contrast to the first discursive phase, responsibility was more often ascribed to the nuclear industry itself, frequently to TEPCO but also to other regulatory authorities.

At this stage of the disaster news cycle far more was known about the progression of the nuclear crisis and the likelihood that the accident would cause significant radioactive contamination beyond the immediate exclusion zone. At this time, the voices of anti-nuclear campaigners in Japan also became louder, and this was reflected in the reporting carried by both The NYT and the Guardian/The Observer (See Tokyo nuclear power company turns toxic: Firm behind Fukushima crisis could be nationalized with bills of up to $£ 74$ billion, the Guardian, 6 April 2011; Official Defends Japan's Response to Disasters, Calling Them Unprecedented, The New York Times, 10 April, 2011).

During this third discursive phase, a cultural framework was less pronounced. A discourse of cultural otherness was reproduced in reporting that 
assessed the post-disaster mood in Japan, in particular through a thematic narrative that presented a picture of post-disaster Japan as one of calm consensus (Argothy, 2003). This was illustrated in a piece in The NYT that explained how Japan had entered a period of jishuku, observed in the exercise of self-restraint (In Deference to Crisis, a New Obsession Sweeps Japan: Self Restraint, The New York Times, 28 March, 2011). The article described how jishuku had led to the cancelation of festivities and also considered its impact on Japan's night-time economy. In doing so the article also drew on some common western images of Japan, with references to cherry-blossom viewing (hanami), karaoke and sushi to name just three examples.

While jishuku is a nuanced concept, a state of 'self-imposed control', (McVeigh, 2014: 115), it is behaviour often ascribed to a period of societal mourning, a collective response to grief. While there is evidence to suggest that jishuku became an established norm in the weeks and months after the disaster (Kingston, 2013), introducing this concept to readers and discussing its implications, reinforced the importance of collectivist values within Japanese society. This served to draw attention to a characteristic often ascribed to Japanese culture when emphasising its difference from western cultural values.

A further theme emerged in this final discursive phase as coverage reflected upon the longer-term implications of the disaster for Japan. Some pieces were pessimistic in both their outlook and tone, recognising how the disaster's economic impact would be more keenly felt by young people (New to Work, Young Inherit Japan's Crises, The New York Times, 1 April 2011) and the continued risk posed by radiation (Japan under pressure on evacuation zone: High radiation level found $40 \mathrm{~km}$ from nuclear plant UN urges authorities to 
consider wider exclusion, the Guardian, 1 April 2011). Others were more positive, carrying stories of survivors that had returned to their homes (City Destroyed and Yet Hopeful, Begins to Move on, The New York Times, 11 April 2011).

\section{Further discussion and conclusion}

This article examined the representation of Japan and disaster-affected communities in the context of US and British media coverage of the Great East Japan Disaster. In particular it considered the extent to which discourses of difference and cultural otherness were reproduced and extend ed through media coverage of this news event.

Through an analysis of reporting carried by The NYT and the Guardian/The Observer, the findings revealed the presence of a cultural framework, premised on a discourse of cultural otherness, which was enacted during the response phase of the disaster cycle to explain how people in Japan were coping in the aftermath of disaster. Characteristic to this discourse were the presence of textual elements that served to underline difference and cultural otherness. This was indicated by a tendency to draw on stereotypes, essentialist interpretations of Japanese culture and through the use of culture as an explanatory framework to provide context to individual stories.

The analysis also presented some evidence to show that this discourse did not go uncontested, a function of media self-reflexivity (Cottle 2014), with several pieces included in the sample evaluating whether these representations may be a product of this dominant discourse on Japan, offering examples of post- 
disaster behaviours that contradict the familiar images presented in the western media.

One explanation for the foregrounding of culture lies in the discursive practices of journalism. Specifically, the structure and features of disaster journalism, where coverage is shaped by journalists' commitment to narratives that enable distant events to resonate with their audience (Gurevitch, Levy and Roeh, 1991: 206). Due to the focus in this research on the quality press and in recognising the knowledge and expertise amongst many journalists that authored pieces included within the sample, in contrast to other studies, the analysis here contends the view that it is a lack of familiarity of the cultural context that leads to distortions in reporting (Louw, 2004).

In this particular case study, a discourse of cultural otherness was most clearly articulated through the human-interest stories that showed how people in Japan were living through the disaster. This chimes with and extends the findings of the existing research that has demonstrated a tendency for international media coverage to represent the other (usually non-western) through the construction of stereotypes when reporting disaster and crisis (Leung and Huang, 2007). In contrast, however, with this existing body of research, the analysis here identifies that news media representations of disaster-affected communities may also take the form of more positive stereotypes. The seemingly calm and orderly response to the disaster in Japan presented a framing that was in stark contrast to the construction of postKatrina New Orleans, which was depicted as lawless and violent (Berger, 2009; Durham, 2008). This juxtaposition of these two significant 'natural disasters', for the US media most significantly, may offer an additional explanation for the 
emphasis placed in coverage of the Japan disaster on altruistic behaviours that were attributed to cultural values.

An important question that remains is whether a cultural framework may have some value if it enables audiences to understand significant news events, their impact or encourages them to seek deeper insights about a country they may be unfamiliar with. Ultimately, this would contribute to greater understanding and empower audiences to identify and question essentialist interpretations of culture.

The analysis also acknowledged how common positions adopted in western media reporting on Japan were also revealed in the coverage of this disaster. Through a discourse of risk, which came to the fore amid growing anxieties over the nuclear situation at Fukushima, an ideological position toward Japan was suggested in the way concerns were expressed about the management of this crisis. This was evident in the strength and tone of criticisms attributed to expert sources, but how they were articulated in the texts, presented as either oppositional voices that offered a negative assessment of the accident and its potential consequences or by assigning blame for the weak response to the accident at Fukushima, to 'Japan' or the 'Japanese', without acknowledging the relevant agencies with responsibility for the crisis.

Analyses comparing Japanese and international media coverage of the nuclear emergency have in a similar vein noted the role of experts, in particular those sanctioned by the Japanese government, in contributing a different tone to coverage in the international media (McNeil, 2013).

As arguably the most significant news story about Japan in recent years, the Great East Japan Disaster provides an important case study through which to 
evaluate how the western media cover Japan. At one level it shows that journalism, even the quality press, continue to reproduce a discourse of cultural otherness and recycle common forms of bias when reporting on Japan. Beyond the more episodic coverage of the post-impact and response phases of the disaster, this discourse, however, became less visible within the media texts.

In conclusion, this article suggests that the use of a cultural framework is not simply inherent to disaster journalism but is also particular to the response phase of the disaster cycle. With the existing literature demonstrating a positive relationship between the amount of coverage and audience knowledge about a news event (Galtung and Ruge, 1965), it is this acute phase of news media coverage that is likely to be most important in shaping audience understanding.

While the focus of this paper is to gain insights into mainstream news media coverage, further research is required to consider whether this discourse of cultural otherness was conveyed or challenged in other discursive spaces, for example in alternative media or through the conversations that occurred across social media (Cottle, 2014). Moreover, the extent to which the image of Japan conveyed through this disaster may be reflected in audience understanding and impressions of Japan. It would also be valuable to consider whether this discourse continues to be present in journalistic narratives through the longerterm recovery phase and in other contexts, in particular given the attention that will be afforded to Japan in the run up to the Tokyo 2020 Olympic Games.

\section{References}

Alexy A (2011). The Door My Wife Closed: Houses, Families, and Divorce in Contemporary Japan. In Home and Family in Japan: Continuity and 
Transformation, Richard Ronald and Allison Alexy (Eds) London: Routledge, pp. $236-253$.

Allan S (2014) Witnessing in crisis: Photo-reportage of terror attacks in Boston and London. Media, War \& Conflict 7(2): 133-151.

Argothy V (2003) Framing volunteerism in a consensus crisis: Mass media coverage of volunteers in the 9/11 response. Disaster Research Center Preliminary Paper (335). University of Delaware.

Bankoff G (2001) Rendering the World Unsafe: 'Vulnerability as Western Discourse. Disasters. 25(1): 19-35.

Bednarek M and Caple H (2014) Why do news values matter? Towards a new methodological framework for analysing news discourse in Critical Discourse Analysis and beyond. Discourse \& Society 25(2): 135-158.

Benthall J (1993) Disasters, Relief and the Media. London: I. B. Tauris.

Berger D (2009) Constructing crime, framing disaster: Routines of criminalization and crisis in Hurricane Katrina. Punishment \& Society 11(4): 491510. 
Breger R. (1992) The discourse on Japan in the German press. Images of economic competition. In: Goodman R and Refsing K (eds) Ideology and practice in modern Japan. London: Routledge, pp. 171-195.

Brown P (2014) SELLING JAPAN IN MAD MEN'S POSTMODERN AMERICA: THE VISUAL TRANSLATION OF JAPANESE ICONS AND IMAGES THROUGH A LENS OF WESTERN ADVERTISING AND AESTHETICS. International Journal of Asia Pacific Studies 10(2).

CISION (2016) Top 10 Daily newspapers. Available at:

http://www.cision.com/us/2014/06/top-10-us-daily-newspapers/ (accessed 1 November 2016).

Chouliaraki L (2006) The spectatorship of suffering. London: SAGE.

Cottle S (2014) Rethinking media and disasters in a global age: What's changed and why it matters. Media, War \& Conflict 7(1): 3-22.

Daliot-Bul M. (2007) Eroticism, Grotesqueness and Non-Sense: Twenty-first Century Cultural Imagery of Japan in the Israeli Media and Popular Culture. Journal of Intercultural Studies 28(2): 173-191.

Di Giovanni E (2003) Cultural Otherness and Global Communication in Walt Disney Films at the Turn of the Century. The Translator 9(2): 207-223. 
Durham F (2008) Media ritual in catastrophic time: The populist turn in television coverage of Hurricane Katrina. Journalism 9(1): 95-116.

Farinosi M and Treré E (2014) Challenging mainstream media, documenting real life and sharing with the community: An analysis of the motivations for producing citizen journalism in a post-disaster city. Global Media and Communication 10:(1) 73-92.

Fairclough N (1995) Media Discourse. London: Edward Arnold.

Fairclough N (2003) Analysing discourse: textual analysis for social research. London: Routledge.

Franks S. (2013) Reporting disasters: famine, aid, politics and the media, London: C Hurst \& Co.

Galtung J and Ruge MH (1965) The Structure of Foreign News. Journal of Peace Research 2(1): 64-90.

Gans HJ (1980) Deciding what's News: a Study of CBS Evening News, NBC Nightly News, Newsweek, and Time. New York: Pantheon Books.

Golan GJ and Lukito J (2015) The rise of the dragon? Framing China's global leadership in elite American newspapers. International Communication Gazette 77(8): 754-772.

Goldstein-Gidoni O (2005) The Production and Consumption of 'Japanese Culture' in the Global Cultural Market. Journal of Consumer Culture 5(2): 155179. 
Guo L, Holton A and Jeong SH (2012) Transnational Comparative Framing: A Model for an Emerging Framing Approach. International Journal of Communication 6(2012): 1918-1941.

Gurevitch M, Levy M and Roeh I (1991) The global newsroom: Convergences and diversities in the globalisations of televisions news. In Dahlgreen P and Sparks C (eds) Communication and citizenship: Journalism and the public sphere in the new media age. Cambridge: Polity Press, pp. 226-243.

Greenberg J and Scanlon TJ (2016) Old Media, New Media, and the Complex Story of Disasters. Oxford Research Encyclopedia of Hazard Science. DOI:

10.1093/acrefore/9780199389407.013.21.

Ha JS (2017) Tailoring the Arab Spring to American values and interests: A framing analysis of U.S. elite newspapers' opinion pieces. International Communication Gazette 79(3): 276-297.

Hammond P (1997) Introduction: questioning cultural difference. In: Hammond P (ed) Cultural difference, media memories: Anglo-American images of Japan, London: Cassell, pp.xi-xxv.

Hammond P and Stirner P (1997) Fear and Loathing in the British Press. In: Hammond P (ed) Cultural difference, media memories: Anglo-American images of Japan, London: Cassell, pp.85-114.

Hendry J (2013) Understanding Japanese society, London: Routledge. 
Himelboim I, Chang T-K and McCreery S (2010) International Network of Foreign News Coverage: Old Global Hierarchies in a New Online World. Journalism \& Mass Communication Quarterly 87: 297-314.

Hinton PR (2014) Representation or misrepresentation?: British media and Japanese popular culture. NECSUS. European Journal of Media Studies 3(1): 89108.

Hinton PR (2016) The Perception of People: Integrating cognition and culture, Abingdon: Taylor \& Francis.

Houston JB, Pfefferbaum B and Rosenholtz CE (2012) Disaster news framing and frame changing in coverage of major US natural disasters, 2000-2010. Journalism \& Mass Communication Quarterly 89 (4): 606-623.

Huang T (2011) Coverage of Japanese citizens' 'stoic' response to tragedy both accurate, stereotypical. Available at: http://www.poynter.org/2011/japanesecitizens-stoic-response-to-tragedy-both-accurate-stereotypical/126006 (accessed 1 November 2016).

Iannarino NT, Veil SR and Cotton AJ (2015) Bringing Home the Crisis: How US Evening News Framed the 2011 Japan Nuclear Crisis. Journal of Contingencies and Crisis Management 23(3): 169-181.

Ibroscheva E and Ramprasad J (2008) Do media matter? A social construction model of stereotypes of foreigners. Journal of Intercultural Communication 16: $1-21$ 
Ishihara S (1991) The Japan That Can Say No: Why Japan Will be the First Among Equals. New York: London: Simon \& Schuster.

Iwabuchi K (1994) Complicit exoticism: Japan and its other. Continuum 8(2): 4982.

Iwabuchi K (2003) Recentering globalization: Popular culture and Japanese transnationalism. Durham, N.C: London: Duke University Press.

Iwabuchi K (2015) Resilient Borders and Cultural Diversity: Internationalism, Brand Nationalism, and Multiculturalism in Japan. Lanham: Lexington Books.

Joye S (2010) News discourses on distant suffering: a Critical Discourse Analysis of the 2003 SARS outbreak. Discourse \& Society 21(5): 586-601.

Kawano S, Roberts GS and Long O (2012) Capturing Contemporary Japan: Differentiation and Uncertainty, Honolulu: University of Hawaii Press.

Kingston J (2013) Contemporary Japan: History Politics and Social Change Since the 1980s. Chichester, West Sussex: John Wiley \& Sons.

Kushida KE (2012) Japan's Fukushima Nuclear Disaster: Narrative, Analysis and Recommendations, Shorenstein APARC Working Papers, Stanford, CA: The Walter H. Shorenstein Asia-Pacific Research Center

Lasorsa D and Dai J (2007) When News Reporters Deceive: The Production of Stereotypes. Journalism \& Mass Communication Quarterly 84(2): 281-298. 
Levick J (2005) Japan in the U.S. Press: Bias and Stereotypes, Japan Digest. http://spice.fsi.stanford.edu/docs/japan_in_the_us_press_bias_and_stereotypes (accessed 1 November 2016).

Leung CCM and Huang Y (2007) The paradox of journalistic representation of the other: The case of SARS coverage on China and Vietnam by western-led Englishlanguage media in five countries. Journalism 8(6): 675-697.

Louw PE (2004) 'Journalists Reporting from Foreign Places', in AS De Beer and JC Merrill (eds) Global Journalism: Topical Issues and Media Systems, White Plains, NY: Allyn \& Bacon, pp. 151-78.

Mayes T and Rowling M (1997) The image makers: British journalists on Japan. In: Hammond P (ed) Cultural difference, media memories: Anglo-American images of Japan, London: Cassell, pp.115-138.

McCormick S. (2016) New tools for emergency managers: an assessment of obstacles to use and implementation. Disasters 40: 207-225.

McCarthy MM (2014) The media, the government and the tripartite disaster of 2011. In: Rausch A (eds) Japanese Journalism and the Japanese Newspaper: A Supplemental Reader. Amherst, NY: Tenno Press, pp.179-196.

McNeil D (2013) Them versus Us: Japanese and international reporting of the Fukushima nuclear crisis. In T. Gill, B. Steger, and D. Slater (Eds.), Japan Copes with Calamity. Oxford: Peter Lang, pp. 127-150. 
Miller JH (2014) American Political and Cultural Perspectives on Japan. From Perry to Obama. Plymouth: Lexington Books.

McVeigh BJ (2014) The Nature of the Japanese State. Routledge.

Moeller S (1996) Pictures of the enemy: Fifty Years of Images of Japan in the American Press, 1941-1992. The Journal of American Culture 19:29-42.

Morris N (2011) Japan-bashing: anti-Japanism since the 1980s, London:

Routledge.

Pantti M, Wahl-Jorgensen K and Cottle S (2012) Disasters and the Media. New York: Peter Lang.

Pantti M (2012) GETTING CLOSER? Journalism Studies 14(2): 201-218.

Philo G (2007) CAN DISCOURSE ANALYSIS SUCCESSFULLY EXPLAIN THE CONTENT OF MEDIA AND JOURNALISTIC PRACTICE? Journalism Studies 8(2): 175-196.

Ploughman P (1995) The American Print News Media 'Construction' of Five Natural Disasters. Disasters 19(4): 308-326.

Press Gazette (2016) NRS Readership Figures: Daily Mail/Mail Online grows UK monthly audience to $29 m$. Available at: http://www.pressgazette.co.uk/nrsreadership-figures-daily-mailmail-online-grows-uk-monthly-audience-to- $29 \mathrm{~m} /$ (accessed 1 November 2016).

Rausch, A (2014). From news to memory creation. In Rausch A (ed.) Japanese 
Journalism and the Japanese Newspaper: A Supplemental Reader.

Amherst, NY: Tenno Press, pp.65-271.

Rees G (2011) Japan: How Resilient a Nation? Dart Centre for Journalism and Trauma. Available at: http://dartcenter.org/content/how-resilient-is-japan (accessed 1 November 2016).

Reese SD and Lewis SC (2009) Framing the War on Terror: The internalization of policy in the US press. Journalism 10(6): 777-797.

Richardson JE (2007) Analysing newspapers: An approach from critical discourse analysis. Basingstoke: Palgrave Macmillan.

Roth JH (2014) Lightweight cars and women drivers: the de/construction of gender metaphors in recessionary Japan. In: Kawano S, Roberts GS and Long 0 (Eds) Capturing Contemporary Japan: Differentiation and Uncertainty, Honolulu: University of Hawaii Press, pp. 300-315.

Roy S (2012) Culturally unconscious: Intercultural implications of The New York Times representation of the Israel-Palestine conflict in 2009 and 2011. International Communication Gazette 74(6): 556-570.

Ryang S (2004) Chrysanthemum's Strange Life: Ruth Benedict in Postwar Japan. Japan Policy Research Institute Occasional Paper 32: 1-13. 
Sakai M (2012) Analysis of Comparative English Media Reports that Related to the Aftermath of the Fukushima Daiichi Nuclear Power Plant Disaster. Sociology and Anthropology. 3(9), 434-439.

Samuels RJ (2013) 3.11: Disaster and Change in Japan. Ithaca, NY: Cornell University Press.

Seaton P (2005) Reporting the 2001 textbook and Yasukuni Shrine controversies: Japanese war memory and commemoration in the British media. Japan Forum 17(3): 287-309.

Seiter E (1986) Stereotypes and the Media: A Re-evaluation. Journal of Communication 36(2): 14-26.

Shoemaker PJ and Reese SD (1991) Mediating the Message: Theories of Influences on Mass Media Content, London: Longman.

Sweeney, M (2014) The Guardian overtakes New York Times in comScore traffic figures, $21^{\text {st }}$ October 2014. Available at: https://www.theguardian.com/media/2014/oct/21/the-guardian-overtakes-newyork-times-in-comscore-traffic-figures (accessed 1 November 2016).

Takekawa, S. (2014) Local newspapers and the post-earthquake and tsunami reconstruction in Iwate Prefecture. In: Rausch A (ed.) Japanese Journalism and the Japanese Newspaper: A Supplemental Reader. Amherst, NY: 
Tenno Press, pp. 217-240.

Tajifel H. (1969) Cognitive Aspects of Prejudice. Journal of Social Issues 25(4): 7997.

Tkach-Kawasaki LM (2012) March 11, 2011 online: comparing Japanese newspaper websites and international news websites. In: Kingston J (ed) Natural Disaster and Nuclear Crisis in Japan: Response and Recovery after Japan's 3/11. London: Routledge, pp.109-123.

van Dijk TA (1988) News as Discourse, London: Lawrence Erlbaum Associates. van Dijk TA (1993) Principles of Critical Discourse Analysis. Discourse \& Society 4(2): 249-283.

van Dijk TA (2009) Critical discourse studies: a sociocognitive approach. In (eds) Wodak R and Meyer M. Methods of critical discourse analysis. London: SAGE, pp. 62-86.

Watanabe K (2013) The western perspective in Yahoo! News and Google News. International Communication Gazette 75(2): 141-156.

Wu HD (2007) A Brave New World for International News? Exploring the Determinants of the Coverage of Foreign News on US Websites. International Communication Gazette 69(6): 539-551. 